\title{
Evidence on Challenges Faced by Manufacturing Informal Sector Micro-Enterprises in Nairobi and Their Relationship with Strategic Choice
}

\author{
Madara Ogot ${ }^{1}$ \\ ${ }^{1}$ School of Business and Economics, Maseno University, Maseno, Kenya \\ Correspondence: Madara Ogot, School of Business and Economics, Maseno University, Private Bag, Maseno, \\ Kenya. E-mail: madaraogot@maseno.ac.ke
}

Received: December 30, 2013

Accepted: April 4, 2014

Online Publication: May 27, 2014

doi: 10.5539/ibr.v7n6p119

URL: http://dx.doi.org/10.5539/ibr.v7n6p119

\begin{abstract}
The study sought to determine the challenges faced by Informal Sector Micro-Enterprises in the manufacturing sector as well as establish what influences, if any, they have on their strategic choice. Porter's competitive business strategy model formed the theoretical framework for strategic choice. A total of 135 enterprises were sampled from six regions in Nairobi, Kenya. From the study, 30 main challenges were identified and ranked. The top three challenges for the sector were Competition, High Cost of Production and Lack of Adequate Capital. A cross-reference with strategic choice found that, enterprises experiencing challenges of High Cost of Production, High Cost of Transport and High Cost of Capital were more likely to adopt focus low cost strategies within Porter's framework. Those experiencing Hard Bargaining Customers were more likely to adopt differentiation focus strategies, while enterprises adopting mixed strategies are more likely to face Consumer Purchasing Power, Dishonest Customers and Theft as their main challenges. The study therefore shows that there does exist a relationship between challenges faced by an informal sector micro-enterprises and their strategic choice.
\end{abstract}

Keywords: informal sector, micro-enterprise, competitive strategies, business challenges

\section{Introduction}

In Sub-Saharan Africa, it is estimated that the informal sector accounts for approximately $90 \%$ of all new jobs and up to $85 \%$ of total employment. The importance of the informal sector in the development of the economies of SSA is backed by empirical evidence (ILO, 2000) with direct links to the countries main objectives of development, employment, wealth creation as well as forming a key strategy for poverty reduction. The sector encompasses a spectrum ranging from those micro-enterprises struggling to survive on one end of the spectrum, to those that are much better off with innovative and expansive technologies at the other. There has been continued interest in the informal economy as it has continued to grow worldwide despite early predictions of its decline. Further, it is beginning to be recognized as key to the promotion of growth and reduction of poverty (Chen, 2005). The Kenya Government (KNBS, 2012) defines the informal sector to 'cover all small- scale activities that are semi-organized, unregulated, and use low and simple technologies.' (p. 78).

A consensus school of thought has emerged on the informal sector (Chen, 2005). Based on the idea of a multi-segmented labour market, it posits that the informal economy is comprised of three main segments, a lower, middle and upper-tier (Bacchetta et al., 2009), '... a lower-tier segment dominated by households engaging in survival activities with few links to the formal economy; an upper-tier segment with micro-entrepreneurs who choose to avoid taxes and regulations; and an intermediate segment with micro-firms and workers subordinated to larger firms. [...] Depending on the regions or countries, the relative importance of each of the segments may vary.' (p. 42) The theoretical framework for this study is based on the emerging consensus school of thought, focussing on micro-enterprises in the intermediate and upper-tier segments, with a view to getting a better understanding the sector through the prism of activity-based business strategy theories. In Kenya, significance of the informal sector is evident from the analysis its contribution to employment in the Country. The sector employed approximately 8.8 million people or $81.1 \%$ in 2010 , up from $79.2 \%$ in 2006 , as summarised in Table 1 (KNBS, 2012).

A consensus definitions of micro and small enterprises (MSEs) has been elusive. There is no uniform definition 
across all economies as the concern with scale or size is only meaningful in a relative or comparative context. Typologies vary widely from one country to the next. The Government of Kenya in the Micro and Small Enterprises Act (2012) defines a micro enterprise as a firm, trade, service industry or business activity whose annual turnover does not exceed Kshs. 500,000, and which employs less than ten people. For those in the manufacturing sector, their investment in plant and machinery or its registered capital should not exceed Kshs 10 million. For the service sector and farming enterprises, the investment in equipment or its registered capital should not exceed Kshs. 5 million shillings. Small enterprises, on the other hand, are a firm, trade, service industry or business activity whose annual turnover ranges between Kshs. 500,000 and Kshs 5 million, and which employs between ten and fifty people. For those in the manufacturing sector, their investment in plant and machinery or its registered capital should range between Kshs. 10-50 million. For the service sector and farming enterprises, the investment in equipment or its registered capital should range between Kshs 5-20 million. These definitions were used to guide this study.

Despite the significant role of informal sector micro and small enterprises (IS/MSEs), few grow to become medium or large size enterprises due to challenges that include lack of access to markets, information on and access to finance; limited access to technology; low education levels of the entrepreneurs; lack of managerial, marketing and production skills; use of rudimentary technology; low-skilled work-base; lack of access to credit; very low purchasing power of their consumers/clients; and regulatory constraints emanating from difficulties of obtaining legal status (Stevenson \& St-Onge, 2006).

Table 1. Summary of employment in both the formal and informal sector (millions)

\begin{tabular}{ccccccc}
\hline & $\mathbf{2 0 0 6}$ & $\mathbf{2 0 0 7}$ & $\mathbf{2 0 0 8}$ & $\mathbf{2 0 0 9}$ & $\mathbf{2 0 1 0}$ \\
\hline Wage Employment & 1.857 & 1.909 & 1.943 & 2.000 & 2.060 \\
$\quad$ Informal Sector & 7.068 & 7.501 & 7.942 & 8.389 & 8.829 \\
\% Informal Sector of Total & 79.2 & 79.7 & 80.3 & 80.7 & 81.1 \\
\hline
\end{tabular}

Source: Compiled from KNBS (2012).

\section{Challenges Faced by Micro and Small Enterprises}

The main factors that may affect the performance of micro and small enterprises (MSEs) in developing countries may be more to do with their isolation, rather than their size. Isolation hinders their access to markets, information, finance and institutional support. Reasons for failure include intense competition and replication of micro enterprises, lack of managerial skills and experience (Katwalo \& Madichie, 2008). Causes of failure may be internal to the firm, and therefore presumably within its control, or external to the enterprise and therefore beyond its control. Internal short-comings should encourage interventions to help enterprises help themselves. On the other hand, external causes may require policy interventions that change the external environment.

Numerous researchers have empirically identified key challenges experienced by micro and small enterprises in various African countries (see Table 2). From the studies it has been shown that local environments, economies and government policies, amongst others, greatly influence the challenges faced. In addition, differences occur between and within sectors located in urban, peri-urban and rural areas. Further, as the aforementioned influencing conditions are continually changing, so will the challenges. Finally, studies identifying challenges often present industry, sector or country averages, ignoring that enterprises, even with the same sector, may face different challenges, depending on the strategies they may have employed, the maturity of the business, etc. There is therefore need for periodic re-assessment of challenges faced by IS/MSEs. The results from this study can be used in identifying the impact (if any) that intervention programmes or policies have had, as well as identify any new challenges that may have emerged. This study, therefore, took a fresh look at the challenges faced by IS/MSE manufacturing enterprises in Nairobi, Kenya. 
Table 2. Summary of challenges faced by MSEs in various African countries

\begin{tabular}{|c|c|}
\hline Author/Context of Study & Identified challenges inhibiting growth and development \\
\hline Roy \& Wheeler (2006) & $\begin{array}{l}\text { Lack of market knowledge and training; limited Access to capital; lack of cooperation } \\
\text { among business partners }\end{array}$ \\
\hline $\begin{array}{l}\text { Bekele \& Worku (2008) } \\
\text { Sample of } 500 \text { MSMEs in five geographical } \\
\text { regions of Ethiopia }\end{array}$ & $\begin{array}{l}\text { Inability to obtain loans from formal banking institutions; inability to convert part of } \\
\text { profit to investment; poor managerial skills; shortage of technical skills; low level of } \\
\text { education }\end{array}$ \\
\hline $\begin{array}{l}\text { Bowen et al. (2009) } \\
198 \text { micro and small enterprises in Nairobi }\end{array}$ & $\begin{array}{l}\text { Increased competition, insecurity, debt collection, lack of credit, power interruptions, } \\
\text { political uncertainty, cost of materials (inputs), hawkers, low demand, unfavourable } \\
\text { business laws, high transportation costs, few customers, low demand }\end{array}$ \\
\hline
\end{tabular}

\section{Competitive Business Strategies}

Generic strategies may be defined as strategies that 'highlight the essential features of separate, situation-specific strategies, capturing their major commonalities in such ways that they facilitate understanding broad strategic patterns. ... at the business level such categorization reduces the myriad variables that demand managerial 'art' to a manageable set of factors with high communality.' (Herbert \& Deresky, 1987, p. 136). The use of generic strategies typologies gained dominance in the late 1970s and early 1980s, with those of and based on Porter (1980) dominating the literature. In the mid to late 1980s, there was a shift in business strategy research towards the resource-based view (RBV) addressing a growing concern among researchers at the limited emphasis placed by the generic strategy typologies on organization specific factors. Resource-based theorists view a resource as anything that could be thought of as a strength or a weakness of a given firm. The usefulness and applicability of generic strategic typologies still remains, however. According to Parnel (2006) the differences between RBV and generic strategy perspectives are not as different empirically as they are conceptually due to the need to assume level of resource value consistency across firms, and assumption that is the basis in strategic group perspectives. In addition, and especially for small firms the RBV may not be generally applicable to them, but better suited for larger firms who can exercise better control over their resources (Ogot \& Mungai, 2012). Due to the dominance of the generic competitive business strategy typologies of, or based-on Porter in the strategic management literature, Porter's framework will form the theoretical framework for strategic choice.

Porter settled on three key generic strategies that a business can adopt: cost leadership, differentiation and market focus. The three strategies can be characterized along two dimensions of competency (cost or differentiation) and market scope (focused or broad). The cost leadership strategy aims to have the lowest price in the target market. To achieve this, while remaining competitive, companies following this strategy must be able to operate at costs lower than their competitors. Differentiation strategies seek to earn above average returns by creating brand loyalty. The latter can serve as a strong entry barrier to competitors. Finally, focus strategies target segments of the market whether a specific consumer group, product line or geographic area. Enterprises were categorized as stuck-in-the-middle if they did not adopt any of the generic strategies.

Ogot \& Mungai (2012) sought to determine the suitability of Porter's competitive business strategies typology to IS/MEs based on micro-enterprise furniture manufactures (metal and wood) in Nairobi, Kenya. Restricting themselves to the focus dimension (as IS/MEs could not become industry leaders either from a differentiation or a low cost perspective due to their very small size) they found that IS/MEs were members of the strategic groups of focus differentiation and focus low cost within Porter's model, with only $15.5 \%$ of the sampled enterprises in the so called 'stuck-in-the-middle' cluster. Porter's model as related to improved business performance did not hold when comparisons were made between the different clusters in the model. Enterprises pursing pure or mixed strategies did not perform better than those pursing none, as would have been expected. The study was limited in that only it was only based on 45 respondents.

This study, therefore, extends the work of Ogot \& Mungai (2012) by establishing and prioritising the challenges faced by IS/ME manufacturing enterprises, as well as determining the influence the identified challenges have on the enterprises strategic choice. Using Porter's framework as a basis for establishing strategic groups, the study establishes whether enterprises employ certain generic strategies (or face particular challenges) as a result of the challenges they face (or the strategies they employ). The study does not establish cause and effect, but determines linkage between strategies employed and challenges faced. 


\section{Research Methodology}

\subsection{Population and Sample of the Study}

The study population was IS/MSE in the furniture manufacturing (wood and metal) in Nairobi, Kenya. As an accurate documented listing of the enterprises is not available, stratified purposeful sampling was used in six representative regions of Nairobi with high concentrations of MSEs: Eastlands, Westlands, Nairobi West, Ngara/Parklands, Dagoretti Corner/Kawangware and Kangemi. Stratification ensured an equal proportion of manufacturing MSEs were included in the sample from each of the representative areas. Using Cochran's (1977) sample size equation for scaled data and populations greater than 10,000 , the minimum sample size was calculated as 119 for a desired accuracy level of $95 \%$ and margin of error of $3 \%$.

Surveys were used for data collection, with oversampling to account for surveys that may not be returned or completed properly yielding a sample size of 135 . The research instrument was inductively derived to be able to determine the challenges faced, and evaluate the extent to which MEs in the informal sector employ each of the competitive business activities that define the two generic strategies of focus differentiation and focus low cost.

\subsection{Research Instrument and Data Analysis}

To determine the challenges, respondents were asked to list in their own words the top three challenges they face. This approach was thought to yield richer results as opposed to asking respondents to rate from a predetermined list. From the ranked list of challenges, cluster analysis is carried out to group similar challenges under a single broader challenge description. Finally the reduced list is used to generate an normalized index for each challenge description, yielding a prioritised list of challenges. In calculating the normalized index, challenges ranked first, second and third were assigned scores of 3, 1.5 and 1, respectively. Each challenge's normalized index was then calculated from Equation 1,

$$
n C_{i}=\operatorname{sum}\left(c_{i j}\right) / \max \left(\operatorname{sum}\left(c_{i j}\right)\right)
$$

where $\mathrm{nC}_{\mathrm{i}}$ and $\mathrm{c}_{\mathrm{ij}}$ are the normalized $\mathrm{i}^{\text {th }}$ Challenge index, and $\mathrm{j}^{\text {th }}$ score of the $\mathrm{i}^{\text {th }}$ challenge, respectively.

To establish strategic choice, respondents were asked to rate on a 4-point Likert-type scale the extent to which they employed several different strategies associated with differentiation focus and low cost focus strategies, where 4-All the time, 3-Often, 2-Occasionally and 1-Never. The strategy statements were based on the competitive business activities seen to be most closely aligned with the differentiation and cost leadership strategic groups as detailed in Ogot \& Mungai (2012). Cluster analysis was then used to establish the extent to which the enterprises employed the competitive business methods associated with each of the strategic groups within Porter's framework. F-Values were then calculated using a one-way ANOVA, to determine the significance of the clustered solutions. Determination of the location of the differences between all mean pairs was done using Scheffe's posterior contrast test that is readily applicable to groups of unequal sizes and relatively insensitive to departures in normality and homogeneity of variances. A similar approach was used by Dess and Davis (1984).

Finally binary logistic regression was used to determine the likelihood that the identified challenges are unique to each of the identified strategic groups. If a respondent had identified a challenge, irrespective of ranking, it was assigned a score of 1, 0 otherwise. Members of a particular strategic group where assigned a 1 , and 0 if not. Binary logistic models were built sequentially by (1) including all the challenges as predictors in the model, (2) starting with predictors at $95 \%$ confidence interval and sequentially building the model by adding predictors at $90 \%, 80 \%, 70 \%$ and $60 \%$ confidence levels, and (3) selecting the model whose likelihood ratio test yields the lowest p-value and therefore the best model fit. This is done for each of the strategic groups. A similar approach was used by Wood (2006) in establishing the internal predictors of business performance in small firms.

\section{Results}

\subsection{Challenges faced IS/MSEs}

The collected top three challenges from each enterprise, were clustered into similar groupings resulting in 30 identified challenges faced by the manufacturing IS/MSEs. Using the previously presented methodology, normalized indices were calculated for each challenge. Results are presented in Table 3. Note that the normalized index provides an indication of the relative significance of each of the identified challenges. From the analysis, the top 3 challenges were 'Competition', 'High Cost of Production' and 'Lack of Adequate Capital', all with normalized scores above 0.5. Numerous previous studies of have shown lack of capital, high cost of capital, or access to capital as the main challenges faced by MSEs (Roy \& Wheeler, 2006; Bekele \& Worku, 2008; and Bowen et al., 2009). This study suggests the 'competition' and 'high cost of production' as the dominant 
challenges for the sector. This may also be due to the selected six regions where the samples where taken have informally evolved into clusters, with large number of enterprises found close together providing similar products.

Table 3. Normalized index for challenges

\begin{tabular}{|c|c|c|c|}
\hline Ranking & Challenge Faced & Variable & Normalized Index \\
\hline 1 & Competition & COMPETITION & 1.00000 \\
\hline 2 & High Cost of Production & PRODUCTION & 0.88716 \\
\hline 3 & Lack of adequate capital & CAPITAL & 0.75875 \\
\hline 4 & Cyclical Demand & DEMAND & 0.45914 \\
\hline 5 & Lack of ready markets & MARKETS & 0.44358 \\
\hline 6 & Hard bargaining customers & BARGAINING & 0.26848 \\
\hline 7 & Shortage of raw materials & MATERIALS & 0.24125 \\
\hline 8 & Dishonest employees & EMPLOYEES & 0.20233 \\
\hline 9 & Government regulations & REGULATIONS & 0.17121 \\
\hline 10 & High Tax & TAX & 0.14397 \\
\hline 11 & Cash Flow & CASH & 0.12451 \\
\hline 12 & Dishonest Customers & DISH CUST & 0.10506 \\
\hline 13 & Keeping accurate books & BOOKS & 0.09339 \\
\hline 14 & High cost of transport & TRANSPORT & 0.08949 \\
\hline 15 & Low consumer purchasing power & CONS PP & 0.05447 \\
\hline 16 & Brokers & BROKERS & 0.05058 \\
\hline 17 & High Cost of Capital & HC CAPITAL & 0.05058 \\
\hline 18 & Theft & THEFT & 0.04669 \\
\hline 19 & Diversion of funds to family commitments & FAMILY & 0.03113 \\
\hline 20 & Staying with market trends & MKT TRENDS & 0.02335 \\
\hline 21 & High Rent & RENT & 0.02335 \\
\hline 22 & Delays in delivery of raw materials & R. MATERIALS & 0.02335 \\
\hline 23 & Security & SECURITY & 0.01946 \\
\hline 24 & Lack of modern equipment & EQUIPMENT & 0.01556 \\
\hline 25 & Market Design Trends & MKT TRENDS & 0.01556 \\
\hline 26 & Quality Control & QUALITY & 0.01556 \\
\hline 27 & Used furniture vendors & VENDORS & 0.01167 \\
\hline 28 & Meeting production deadlines & DEADLINES & 0.01167 \\
\hline 29 & Poor Location & LOCATION & 0.00778 \\
\hline 30 & Lack of government Support & GOVERNMENT & 0.00778 \\
\hline
\end{tabular}

\subsection{Strategic Group Membership}

Based on the methodology presented earlier, four enterprise clusters were identified: pure differentiation with group membership only in the differentiation focus strategic group; pure low cost with group membership only 
in the low cost focus strategic group; mixed strategies with group membership in both the differentiation and low cost focus strategic groups; and stuck-in-the-middle with enterprises not belonging to either of the other strategic groups. Significance of the cluster differences were done using one-way ANOVA using Scheffe's posterior tests with an emphasis on the low cost focus or differentiation focus strategies with results are presented in Table 4 and 5. For analysis emphasing differentiation focus strategies, (Table 3) all clusters show significant difference with each other at $p<0.0000$, except for between the differentiation focus and mixed strategies clusters, and between low cost and stuck-in-the-middle clusters, where there is no significant difference. This is an expected result as for the former, enterprises in both clusters adopt differentiation focus strategies and there would therefore be significant overlap. For the latter, neither cluster emphasises differentiation leading to no differences between them, based on differentiation strategies.

For emphasis on low cost focus strategies (Table 5), all clusters show significant difference with each other at $p<0.0000$, except for the low cost focus and mixed strategies and between differentiation and stuck-in-the-middle. The former is expected as enterprises in both clusters adopt low cost focus strategies. For the latter, neither cluster emphasises low cost, and therefore on would not expect differences between them based on low cost strategies. In addition and with reference to Table 4, only clusters 1 and 3 showed a positive centroid deviation for enterprises with an emphasis on focus differentiation strategies thereby supporting membership in the focus differentiation strategic group by enterprises in the two clusters.

Finally, clusters 2 and 3 showed a positive deviation for enterprises emphasizing low cost focus strategies, in Table 5, supporting membership in that strategic group. Note that cluster 3 (mixed strategic groupP enterprises collectively had positive centroid deviation for enterprises emphasizing both types of strategies, implying application of both low cost focus and differentiation focus strategies. Cluster 4 (stuck-in-the-middle) enterprises, however, collectively had negative centroid deviation for both emphases, implying lack that they neither applied focus low cost nor a focus differentiation strategies.

These strategic groups will therefore form the basis for binary logistic regression against the identified challenges.

Table 4. Mean cluster deviations from differentiation centroids and ANOVA using Scheffe F-test for differences between clusters ( $p$-values in brackets) on cluster deviations based on differentiation centroids

\begin{tabular}{ccccc}
\hline & $\begin{array}{c}\text { Cluster 1: } \\
\text { Differentiation }\end{array}$ & Cluster 2: Low Cost & Cluster 3: Mixed & $\begin{array}{c}\text { Cluster 4: } \\
\text { 'Stuck-in-the-middle' }\end{array}$ \\
\hline Mean & 0.220 & -0.385 & 0.163 & -0.458 \\
Standard Dev. & 0.2088 & 0.3683 & 0.4530 & 0.3487 \\
$n$ & 10 & 53 & 49 & 24 \\
Cluster 1: & & $80.6712(0.0000)$ & $0.1295(0.9424)$ & $83.5810(0.0000)$ \\
Cluster 2: & & $36.5791(0.0000)$ & $0.4842(0.6937)$ \\
Cluster 3: & & & & $42.0703(0.0000)$ \\
\hline
\end{tabular}

Table 5. Mean cluster deviations from low cost centroids and ANOVA using Scheffe F-test for differences between clusters ( $p$-values in brackets) on cluster deviations based on low cost centroids

\begin{tabular}{ccccc}
\hline & $\begin{array}{c}\text { Cluster 1: } \\
\text { Differentiation }\end{array}$ & Cluster 2: Low Cost & Cluster 3: Mixed & $\begin{array}{c}\text { Cluster 4: } \\
\text { 'Stuck-in-the-middle' }\end{array}$ \\
\hline Mean & -0.450 & 0.2610 & 0.3605 & -0.2847 \\
Standard Dev. & 0.4412 & 0.2941 & 0.4197 & 0.4068 \\
$n$ & 10 & 53 & 49 & 24 \\
Cluster 1: & & $115.5248(0.0000)$ & $438.1556(0.0000)$ & $1.7517(0.1595)$ \\
Cluster 2: & & $0.5516(0.6479)$ & $343.1608(0.0000)$ \\
Cluster 3: & & & $207.2885(0.0000)$ \\
\hline
\end{tabular}




\subsection{Binary Logistic Regression}

The binary logistic regression sought to sequentially build models to determine which of the identified challenges can serve as predictors of membership (or not) in a particular strategic group. The results are therefore presented for each of the four groups. Due to the large number of predictors (the challenges) only the top 20 based on the normalized index will be used.

For the low cost focus strategic group the top 20 challenges were regressed as predictors. Sequential model building was then carried out starting with predictors at the $95 \%$ level and sequentially adding predictors at the $90 \%, 80 \%, 70 \%$ and $60 \%$ levels. A summary of the results and the utilized challenges are presented in Table 6 . From the results Model 4 had the best fit based on the likelihood ratio rest $(\mathrm{p}=0.0009)$, retaining the variables PRODUCTION, TAX, BARGAINING, TRANSP, CAPITAL and CONS. PP. The coefficients and p-values for the variables in model 4 are presented in Table 7. For the differentiation focus strategic group, a summary of the sequential model building results are presented in Table 8. From the results Model 7 had the best fit based on the likelihood ratio rest $(\mathrm{p}=0.0055)$, retaining only the BARGAINING variable. The coefficient and $\mathrm{p}$-value for the variables in model 7 are presented in Table 9. Similarly, for the mixed strategic group, sequential model results are summarized in Table 10. From the results Model 13 had the best fit based on the likelihood ratio rest $(\mathrm{p}=0.0520)$, retaining only the CONS PP, DISH CUST and THEFT variables. The coefficient and $\mathrm{p}$-value for the variables in model 13 are presented in Table 11.

Finally, for those enterprises stuck-in-the-middle, a summary of the results from sequential model building are presented in Table 12. From the results Model 17 had the best fit based on the likelihood ratio rest $(\mathrm{p}=0.0027)$, retaining only the PRODUCTION, TAX, TRANSP and CAPITAL variables. The coefficient and p-value for the variables in Model 17 are presented in Table 13. A summary of the best fitting models and their predictors of exclusion from or inclusion in each of the strategic groups is presented in Table 14. The models only include those variables whose effect is above $85 \%$ level of significance. As noted by Wood (2006), however, the use of logit models and coding into binary categories may make the interpretation of the models' coefficients difficult. One should therefore focus on each variable's relative importance, rather than direct application of the statistical model.

Table 6. Sequential Binary logistic model building summary for predictors of the low cost strategic group

\begin{tabular}{ccccc}
\hline Model & Variables in Model & $\begin{array}{c}\text { Likelihood ratio test } \\
\text { statistic }\end{array}$ & $\begin{array}{c}\text { Degrees of } \\
\text { Freedom }\end{array}$ & $\begin{array}{c}\text { P-value (fit of } \\
\text { model) }\end{array}$ \\
\hline 1 & All & 30.4059 & 20 & 0.0635 \\
2 & Over 95\% significance: PRODUCTION, TAX & 12.9001 & 2 & 0.0016 \\
3 & Over 80\% significance: Above plus BARGAINING, & 18.4463 & 4 & 0.0010 \\
& TRANSPORT & & 0.0009 \\
4 & Over 70\% significance: Above plus CAPITAL, CONS. PP & 22.7085 & 6 & 0.0033 \\
\hline
\end{tabular}

Table 7. Final model (Model 4) Binary logistic regression results for predictors of the low cost strategic group

\begin{tabular}{lccc}
\hline Predictor & Estimator & z-value & p-value \\
\hline PRODUCTION & 1.1214 & 2.739 & 0.00617 \\
TAX & -1.9861 & -1.846 & 0.06482 \\
BARGAINING & -0.8329 & -1.405 & 0.16002 \\
TRANSP & 1.2693 & 1.422 & 0.15489 \\
CAPITAL & 0.7922 & 1.844 & 0.06513 \\
CONS.PP & -1.2135 & -0.985 & 0.32486 \\
\hline
\end{tabular}


Table 8. Sequential Binary logistic model building summary for predictors of the differentiation strategic group

\begin{tabular}{llccc}
\hline Model & Variables in Model & $\begin{array}{c}\text { Likelihood ratio test } \\
\text { statistic }\end{array}$ & $\begin{array}{c}\text { Degrees of } \\
\text { Freedom }\end{array}$ & $\begin{array}{c}\text { P-value (fit of } \\
\text { model) }\end{array}$ \\
\hline 6 & All & 21.9663 & 20 & 0.3423 \\
7 & Over 95\% significance: BARGAINING & 7.7072 & 1 & 0.0055 \\
8 & Over 80\% significance: As above plus COMPETITION, & 11.6858 & 4 & 0.0199 \\
& REGULATIONS, BROKERS & & 5 & 0.0234 \\
\hline
\end{tabular}

Table 9. Final model (Model 7) Binary logistic regression results for predictors of the differentiation strategic group

\begin{tabular}{cccc}
\hline Predictor & Estimator & z-value & p-value \\
\hline BARGAINING & 0.8116 & 2.853 & 0.00433 \\
\hline
\end{tabular}

Table 10. Sequential Binary logistic model building summary for predictors of the mixed strategic group

\begin{tabular}{ccccc}
\hline Model & Variables in Model & $\begin{array}{c}\text { Likelihood ratio test } \\
\text { statistic }\end{array}$ & $\begin{array}{c}\text { Degrees of } \\
\text { Freedom }\end{array}$ & $\begin{array}{c}\text { P-value (fit of } \\
\text { model) }\end{array}$ \\
\hline 10 & All & 21.4385 & 20 & 0.3717 \\
11 & Over 95\% significance: CONS PP & 3.6916 & 1 & 0.0547 \\
12 & Over 90\% significance:Above plus DISH CUST & 5.5493 & 2 & 0.0624 \\
13 & Over 80\% significance: Above plus THEFT & 7.7278 & 3 & 0.0520 \\
14 & Over 70\% significance: Above plus BOOKS, BROKERS, & 10.6859 & 7 & 0.1529 \\
\hline
\end{tabular}

Table 11. Final model (Model 13) Binary logistic regression results for predictors of the mixed strategic group

\begin{tabular}{cccc}
\hline Predictor & Estimator & z-value & p-value \\
\hline CONS.PP & 2.3206 & 2.213 & 0.0269 \\
DISH.CUST & 1.4043 & 1.57 & 0.1164 \\
THEFT & 2.3206 & 1.601 & 0.1093 \\
\hline
\end{tabular}

Table 12. Sequential Binary logistic model building summary for predictors of the stuck-in-the-middle strategic group

\begin{tabular}{llccc}
\hline Model & \multicolumn{1}{c}{ Variables in Model } & $\begin{array}{c}\text { Likelihood ratio test } \\
\text { statistic }\end{array}$ & $\begin{array}{c}\text { Degrees of } \\
\text { Freedom }\end{array}$ & $\begin{array}{c}\text { P-value (fit of } \\
\text { model) }\end{array}$ \\
\hline 15 & All & 35.5419 & 20 & 0.3786 \\
16 & Over 95\% significance: PRODUCTION & 7.8397 & 1 & 0.0051 \\
17 & Over 90\% significance: Above plus TAX & 10.7498 & 2 & 0.0046 \\
18 & Over 80\% significance: Above plus TRANSP, CAPITAL & 16.2630 & 4 & 0.0027 \\
19 & $\begin{array}{l}\text { Over 70\% significance: Above plus HC CAPITAL, DISH. } \\
\text { CUST, MARKETS }\end{array}$ & 21.7708 & 7 & 0.0028 \\
20 & $\begin{array}{l}\text { Over 60\% significance: Above plus THEFT, } \\
\text { COMPETITION }\end{array}$ & 23.6139 & 9 & 0.0050 \\
\hline
\end{tabular}


Table 13. Final model (Model 18) Binary logistic regression results for predictors of the stuck-in-the-middle strategic group

\begin{tabular}{cccc}
\hline Predictor & Estimator & z-value & p-value \\
\hline PRODUCTION & -1.12 & -2.808 & 0.00499 \\
TAX & 0.8592 & 1.319 & 0.18721 \\
TRANSP & -1.6275 & -1.457 & 0.14518 \\
CAPITAL & -0.6508 & -1.545 & 0.12227 \\
\hline
\end{tabular}

Table 14. Challenges as predictors of inclusion or exclusion from porters framework strategic groups

\begin{tabular}{ccc}
\hline Strategic Group & Predictor of Inclusion & Predictor of Exclusion \\
\hline Low Cost Focus & PRODUCTION, TRANSP, CAPITAL & TAX, BARGAINING \\
Differentiation Focus & BARGAINING & \\
Mixed & CONS. PP, DISH CUST, THEFT & \\
Stuck-in-the-middle & & PRODUCTION, TRANSP, CAPITAL \\
\hline
\end{tabular}

\section{Discussion}

The study sought to determine the challenges faced by IS/MSEs in the manufacturing sector in Nairobi, Kenya as well as establish what influences, if any, the challenges have on the enterprises strategic choice. Porter's model formed the theoretical framework for strategic choice. From the study, 30 challenges were identified and ranked. The top three challenges were Competition, High Cost of Production and Lack of Adequate Capital. Despite numerous Government interventions such as the establishment of several funds over the last 10 years aimed at making capital more readily available for MSEs (for example the Youth Enterprise Fund, Women Enterprise Fund, the Uwezo Fund) lack of adequate capital still remains a significant challenge. The inability of these funds to meet the capital needs may be due to the lending criteria which, amongst others, is based on group lending (and therefore group responsibility on repayment). Although this practice reduces the default rate, it looks out individual entrepreneurs, most of whom formed the population of this study. Funding mechanisms should therefore be put in place for MSEs who are not members of groups, and who form the majority of enterprises in the Country.

Enterprises that experience 'lack of adequate capital', 'high cost of transport' and 'high cost of production' are more likely to be those who belong to the low cost focus strategic group. These challenges show that in pursuit of a low cost strategy, costs at all stages in the value bring pressure to bear on the managers/owners as they seek to keep the down in order to maintain low prices as seen by the consumer. Those enterprises that experience 'hard bargaining customers' are more likely to be in the differentiation focus strategic group. As expected enterprises pursuing a differentiation strategy will tend to have higher prices due to the uniqueness of their products on offer, resulting in customers seeking to bargain for lower prices. Finally, enterprises experiencing 'low consumer purchasing power', 'dishonest customers' and 'theft' are likely to be in the mixed strategic group. The combination of strategies may seek to mitigate against these set of challenges. It is worth noting that the stuck-in-the-middle enterprises had no unique predictors of inclusion based on the identified challenges.

Finally, this study has contributed to the literature by determining current challenges faced by the sector, as well as demonstrating from industries within the informal sector, there are linkages between challenges faced on strategies adopted.

\section{Acknowledgement}

I acknowledge the support of Universities Denmark and the Building Stronger Universities (BSU) Initiative in putting this paper together.

\section{References}

Bacchetta, M., Ernst, E., \& Bustamante, J. P. (2009). Globalization and Informal Jobs in Developing Countries. 
International Labour Organisation and World Trade Organisation, Geneva.

Bekele, E., \& Worku, Z. (2008). Women Entrepreneurship in Micro, Small and Medium Enterprises: The Case of Ethiopia. Journal of International Women's Studies, 10(2), 3-19.

Bowen, M., Morara, M., \& Mureithi, S. (2009). Management of Business Challenges Among Small and Micro-Enterprises in Nairobi-Kenya. KCA Journal of Business Management, 2(1), 16-31. http://dx.doi.org/10.4314/kjbm.v2i1.44408

Chen, M. (2005). Rethinking the Informal Economy: Linkages with the Formal Economy and the Formal Regulatory Environment. Research Paper, UNU-WIDER, United Nations University, No. 5, 2005/10.

Cochran (1977). Sampling Techniques (3rd ed.). New York: Wiley.

Dess, G. G., \& Davis, P. S. (1984). Porter's (1980) generic strategies as determinants of strategic group membership and organizations performance. Academy of Management Journal, 27, 467-488. http://dx.doi.org/10.2307/256040

Herbert, T., \& Deresky, H. (1987). Generic strategies: An empirical investigation of typology validity and strategy content. Strategic Management Journal, 8(2), 135-147. http://dx.doi.org/10.1002/smj.4250080205

International Labour Organization (ILO). (2000). Resolution concerning statistics of employment in the informal sector. Adopted by the Fifteenth International Conference of Labour Statisticians (January 1993), in Current International Recommendations on Labour Statistics, Geneva:ILO.

Katwalo, A. M., \& Madichie, N. O. (2008). Entrepreneurial and cultural dynamics: a gender kaleidoscope of Uganda micro enterprises. International Journal of Entrepreneurship and Small Business, 5(3), 337-348. http://dx.doi.org/10.1504/IJESB.2008.017307

KNBS. (2012). Statistical Abstracts and Economic Surveys 2011. Nairobi: Kenya National Bureau of Statistics.

Mungai, E., \& Ogot, M. (2012). Gender, Culture and Entrepreneurship. International Business Research, 5(5), 175-183. http://dx.doi.org/10.5539/ibr.v5n5p175

Ogot, M., \& Mungai, E. (2012). Does Porter's Competitive Business Strategies Model Apply to Micro-Enterprises? A study of Furniture Makers in the Informal Sector in Nairobi, Kenya. African International Business and Management Conference, Nairobi, July 12-13.

Parnel. (2006). Generic Strategies after Two Decades: A Reconceptualization of Competitive Strategy. Management Decision, 44(8), 1139-1154. http://dx.doi.org/10.1108/00251740610690667

Porter, M. E. (1980). Competitive strategy: Techniques for analyzing industries and competitors. New York: The Free Press.

Roy, M. A., \& Wheeler, D. (2006). A Survey of Micro-Enterprise in Urban West Africa: Drivers shaping the sector. Development in Practice, 16(5), 452-464. http://dx.doi.org/10.1080/09614520600792432

Stevenson, L., \& St-Onge, A. (2006). Support for Growth-Oriented Women Entrepreneurs in Ethiopia, Kenya and Tanzania, an Overview Report. Geneva: International Labour Organization.

Wood, E. H. (2006). The Internal Predictors of Business Performance in Small Firm: A Logistic Regression Analysis. Journal of Small Business and Enterprise Development, 13(3), 44-453. http://dx.doi.org/10.1108/14626000610680299

\section{Copyrights}

Copyright for this article is retained by the author(s), with first publication rights granted to the journal.

This is an open-access article distributed under the terms and conditions of the Creative Commons Attribution license (http://creativecommons.org/licenses/by/3.0/). 